\title{
APPLICATIONS OF A $(k-\varepsilon)$ MODEL FOR THE ANALYSIS OF CONTINUOUS CASTING PROCESSES
}

\author{
MARCELA B. GOLDSCHMIT*, R. JAVIER PRINCIPE AND MARISOL KOSLOWSKI \\ Center for Industrial Research, FUDETEC, Av. Córdoba 320, 1054 Buenos Aires, Argentina
}

SUMMARY

The finite element solution of the turbulent Navier-Stokes equations developed via $(k-\varepsilon)$ turbulence models was addressed in previous publications [1-4], where a $(k-L)$-predictor $/(\varepsilon)$-corrector iterative algorithm was developed. It was shown that the developed algorithm is robust and converges for the analyses of different flows without requiring the implementation of ad hoc numerical procedures. The turbulent convection-diffusion transport equations are solved by using the velocity distributions determined from the solution of the turbulent Navier-Stokes equations. The dispersion of a die in a turbulent flow can therefore be modelled and the obtained dispersion patterns are validated via flow visualizations in water models. In the present paper, the developed analysis capability is applied to the analysis of continuous casting processes. Copyright (C) 1999 John Wiley \& Sons, Ltd.

KEY WORDS: turbulence models; continuous casting; computational fluid dynamics

\section{INTRODUCTION}

The liquid steel flow behaviour largely determines the quality and productivity of the steelmaking process. The analysis of liquid steel flows in continuous casting installations using water models and numerical models [5-13] increases the knowledge on a particular industrial installation, enabling engineers to:

(1) study the effect of different variables on the process output;

(2) increase the process efficiency as regards materials and energy consumption;

(3) improve the equipment design;

(4) etc.

To depict the fact that most of the liquid steel flows are in the turbulent regime in the installation in Figure 1, we consider the submerged entry nozzle (SEN) example:

(a) internal nozzle diameter, $d_{\mathrm{b}}=0.04 \mathrm{~m}$;

\footnotetext{
* Correspondence to: Marcela B. Goldschmit, Center for Industrial Research, FUDETEC, Av. Córdoba 320, 1054 Buenos Aires, Argentina. E-mail: sidgld@siderca.com

Contract/grant sponsor: SIDERCA

Contract/grant sponsor: TAMSA

Contract/grant sponsor: SIDERAR
}

CCC 0029-5981/99/331505-15\$17.50

Copyright (C) 1999 John Wiley \& Sons, Ltd.

Received 1 September 1998

Revised 1 February 1999 
(b) liquid steel flow rate in the mold, $q_{\mathrm{b}}=0.001 \mathrm{~m}^{3} / \mathrm{s}$;

(c) mean velocity in the nozzle, $v_{\mathrm{b}}=q_{\mathrm{b}} /\left(\pi d_{\mathrm{b}}^{2} / 4\right)=0.796 \mathrm{~m} / \mathrm{s}$;

(d) kinematic viscosity, $\mu / \rho=9 \cdot 31 \mathrm{E}-7 \mathrm{~m}^{2} / \mathrm{s}$;

(e) Reynolds number, $\operatorname{Re}=\left(v_{\mathrm{b}} d_{\mathrm{b}} \rho\right) / \mu=34200$ (well inside the turbulent regime).

The main characteristics of the turbulent flow are the random fluctuations in the variables (fluid velocity, pressure, etc.) so that statistically distinct averages can be discerned. The fluctuations are due to a continuous generation and movement of eddies in the flow. It is worth pointing out that a turbulent flow is described by the usual continuum mechanics equations because the smallest length scales in a turbulent flow are much higher than the molecular length scales.

In order to solve the problem, the mathematical description of a turbulent flow using the time-averaged Navier-Stokes equations leads to the development of turbulence models. These turbulence models do not simulate the details of the turbulent motion but they do simulate the effect of turbulence on the mean-flow behaviour.

The classical $(k-\varepsilon)$ turbulent model in conjunction with the method of wall functions developed by Launder and Spalding [14] is usually used to model liquid steel flows in continuous casting installations [5-13]; where $k$ is the turbulent kinetic energy and is the turbulent kinetic energy dissipation rate.

The literature [15-18] of the partial differential $\varepsilon$-transport equations. To algorithm, referred to as $(k-L)$-predictor/( $\varepsilon)$-corrector scheme [1-4]; w The algorithm was implemented in the finite element code FAN
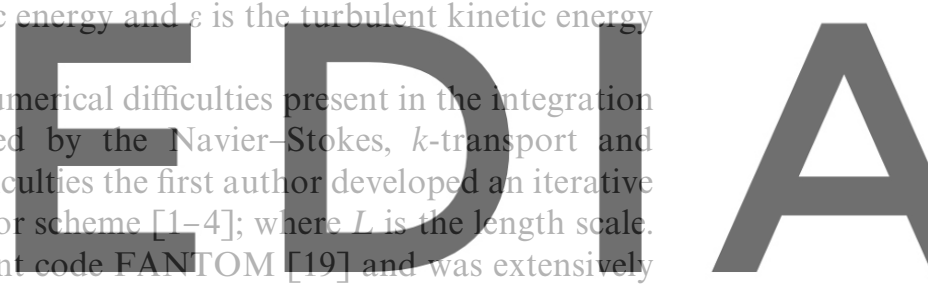
tested to demonstrate its robustness and reliability.

Register for free at https//www.scipedia.com to download the version without the waterma

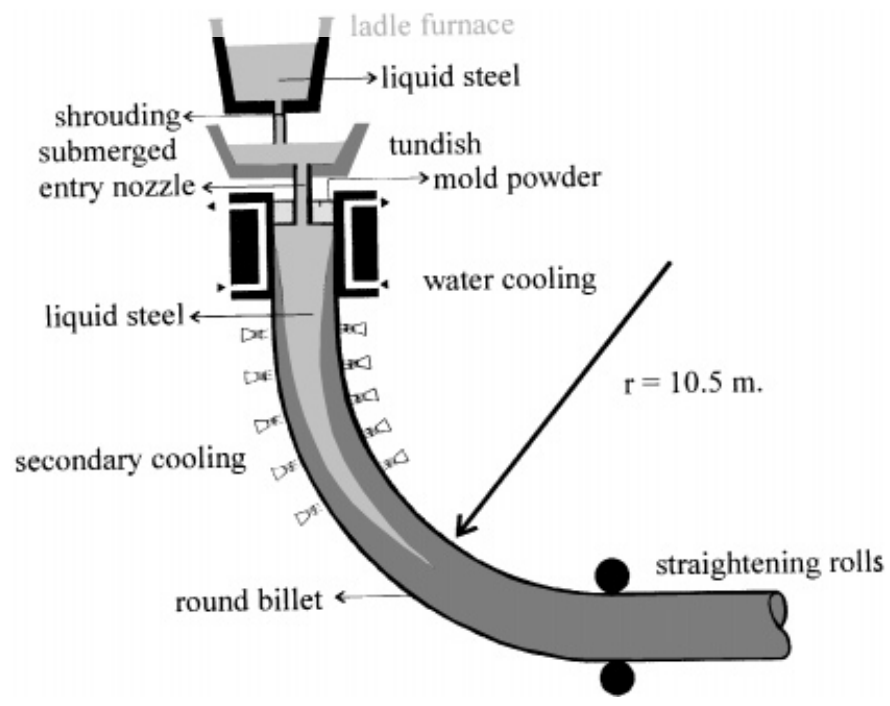

Figure 1. Round bars continuous casting installation 
In this iterative scheme a predictor result is obtained using a $k-L$ model and it is later corrected integrating the $\varepsilon$-transport equation. The iterative scheme loops between predictor and corrector phases until convergence is achieved in the length scale.

When using water models to simulate different continuous casting processes [20-22], the flow is visualized by injecting a die or another substance upstream and then using photographs, conductivity measurements, etc. to study the transport of the injected substance by the fluid flow. In order to match the experimental determinations when using mathematical models, a convection-diffusion equation $[23,24]$ is solved thus describing the transport of the injected substance by the incompressible turbulent flow. In this paper three industrial applications will be considered:

1. The analysis of different options for the SEN in the mold of round bars continuous casting mill at SIDERCA (Campana, Argentina) and TAMSA (Veracruz, Mexico).

2. The analysis of one SEN design operating with different mold sizes in the slabs continuous casting at SIDERAR (San Nicolas, Argentina).

3. The tundish of a continuous casting installation at SIDERCA.
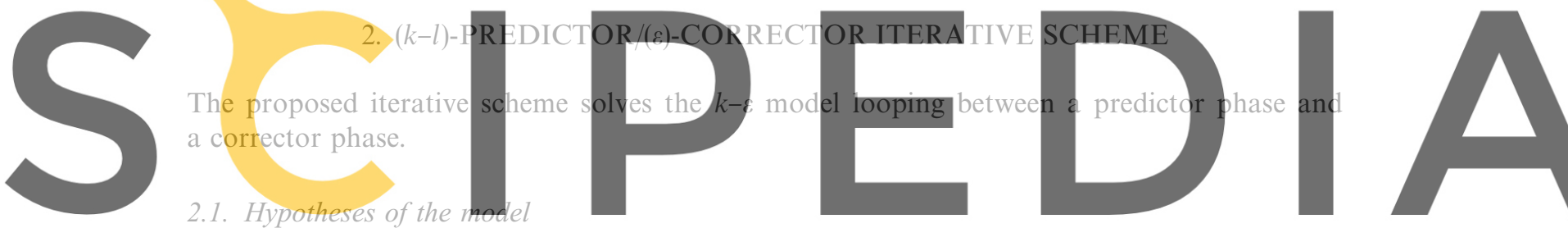

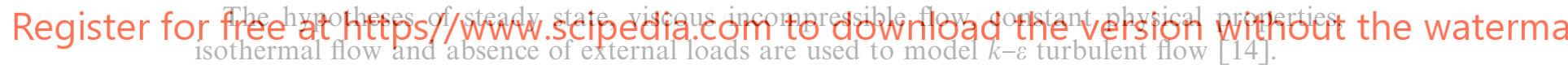

\section{2. (k-L) Predictor phase}

The predictor phase is the solution of a $(k-L)$ turbulence model.

Continuity equation

$$
\boldsymbol{\nabla} . \mathbf{v}=0
$$

Navier-Stokes equation

$$
\rho \mathbf{v} \cdot \nabla \mathbf{v}-\nabla \cdot\left[\left(\mu+\mu^{\mathrm{t}}\right)\left(\nabla \mathbf{v}+\nabla \mathbf{v}^{\mathrm{T}}\right)\right]+\nabla P=\mathbf{0}
$$

Transport equation for the turbulent kinetic energy $(k)$

$$
\rho \mathbf{v} \cdot \nabla k-\nabla \cdot\left[\left(\mu+\frac{\mu^{\mathrm{t}}}{\sigma_{k}}\right) \nabla k\right]-\mu^{\mathrm{t}}\left(\nabla \mathbf{v}+\nabla \mathbf{v}^{\mathrm{T}}\right): \nabla \mathbf{v}+\rho \frac{C_{\mu} k^{2}}{\mu^{\mathrm{t}} / \rho}=0
$$

Turbulent or eddy viscosity $\left(\mu^{\tau}\right)$

$$
\mu^{\mathrm{t}}=C_{\mu} \rho \sqrt{k} L
$$


The length scale, $L$

$$
L=\frac{k^{3 / 2}}{\varepsilon}
$$

where $\rho$ is the density, $\mu$ the molecular viscosity, $\mathbf{v}$ the time-averaged velocity, $P=p+2 / 3 k$; $p$ is the time-averaged flow pressure.

The empirical constants of the $(k-L)$ model are the typical ones determined by Launder and Spalding [14]: $C_{\mu}=0 \cdot 99, \sigma_{k}=1 \cdot 0$.

To solve this predictor phase the $\varepsilon$ value from the previous corrector phase is used.

2.2.1. Wall functions. The affected viscous near-wall region where the $k-\varepsilon$ model is no longer valid is handled using the well-established 'wall function method' of Launder and Spalding [14] which has been extensively used with his turbulence model [25-31].

The first nodes of the finite element mesh close to the walls are placed at a distance $\Delta$ from the walls and the velocity component parallel to the wall at the node $P$ is given by
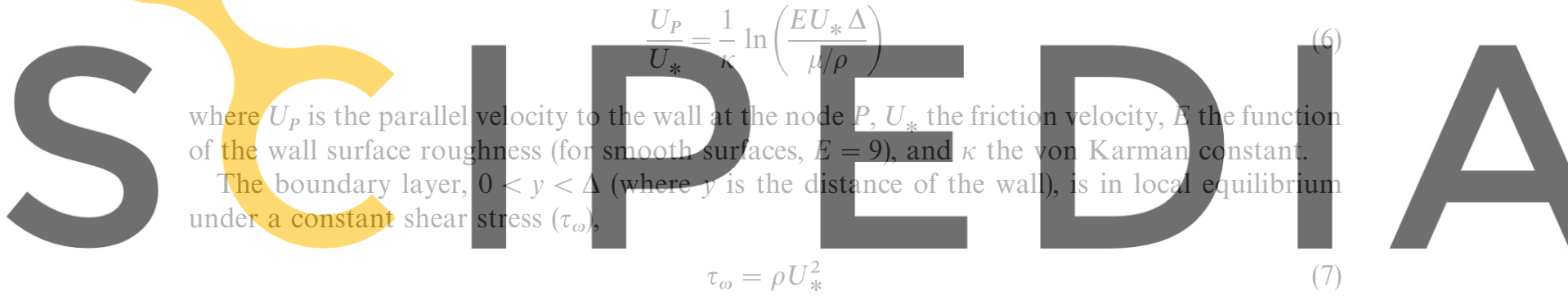

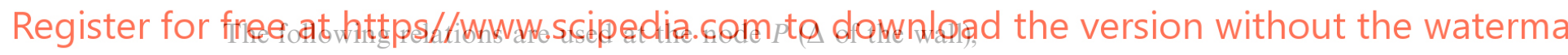

$$
\begin{gathered}
k_{P}=\frac{U_{*}^{2}}{C \mu} \\
\varepsilon_{P}=\frac{U_{*}^{3}}{\kappa \Delta}
\end{gathered}
$$

In the iterative predictor phase, with $U_{P}$ obtained from the previous iteration in the $k-L$ model, $U_{*}$ is calculated from equation (6) using the Newton-Raphson technique for each node $P$ near the wall. The values of $\tau_{\omega}$ and $k_{P}$ are calculated using the equations (7)-(8) and are used as boundary conditions for the following predictor iteration of the $k-L$ model.

The velocity component normal to the node $P$ near the wall is set to zero $[1-4,25,27,28,30,31]$ not taking into account the mass transfer in the viscous sublayer. An alternative approach reported in the literature [28] is to approximate this mass transfer by evaluating the normal component of the velocity from continuity considerations [32].

The limitation of the approach adopted in this paper becomes more apparent when the complexity of the flow increases; and this limitation is very severe when there is a subtle separation, as shown by Haroutinian and Engelman [33], who compared the wall function method with an alternative approach developed by them which seems to extend the applicability of the $k-\varepsilon$ model. The limitation is shown using the $(k-L)$-predictor $/(\varepsilon)$-corrector scheme in the 
plane $U$-channel example where the location of the separation point in the recirculating zone is not geometrically determined [2].

\section{3. (ع) Corrector phase}

In this phase we solve the transport equation for $\varepsilon$, Transport equation for the turbulent kinetic energy dissipation rate $(\varepsilon)$

$$
\rho \mathbf{v} \cdot \nabla \varepsilon-\nabla .\left[\left(\mu+\frac{\mu^{\mathrm{t}}}{\sigma_{\varepsilon}}\right) \nabla_{\varepsilon}\right]-\rho C_{\mu} C_{1} k\left(\nabla \mathbf{v}+\nabla \mathbf{v}^{\mathrm{T}}\right): \nabla \mathbf{v}+\rho \frac{C_{2} \varepsilon^{2}}{k}=0
$$

The empirical constants [14] are, $C_{1}=1 \cdot 44 ; C_{2}=1 \cdot 92 ; \sigma_{\varepsilon}=1 \cdot 3$.

The boundary conditions at the nodes $P$ associated to wall functions are $\varepsilon_{P}$, equation (9).

\subsection{Iterative algorithm}

The proposed iterative scheme loops between a predictor phase ( $k-L$ model) and a corrector phase ( $\varepsilon$ transport equation) and updates the value of $L$ using an underrelaxation technique (s Table I).

The transport equations $[35-37]$ and a standard
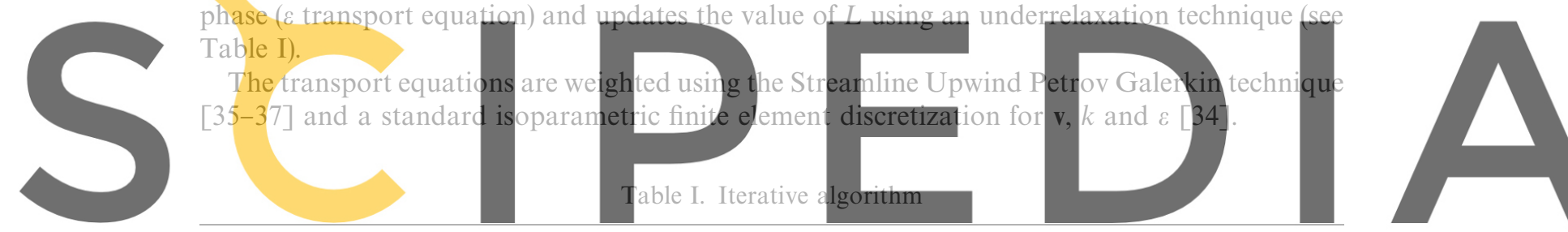

Starting procedure $i=0$ ( $i$ is iteration counter)

Register for free at https $/ / \mathrm{v}^{(0)}$ WW.

(a) $i=i+1$

$(k-L)$-Predictor phase $j=0(j$ is predictor iteration counter $)$

(b) $j=j+1$

Solve Navier-Stokes equations (equation (1)-(2); using a penalty formulation to impose the incompressibility constraint [34]).

Solve the wall function (equation (6) for each node associated to a wall, using the Newton-Raphson technique determine $U_{*}$ ).

Determine $\tau_{\omega}, k_{\mathrm{P}}$ and $\varepsilon_{\mathrm{P}}$ from equations (7)-(9).

Update $\mu^{\mathrm{t}}$ from equation (4).

Solve the transport equation of $k$ (equation (3)).

Update $\mu^{\mathrm{t}}$ from equation (4).

Repeat from (b) until convergence of $k-L$ model is achieved

(ह)-Corrector phase $\quad m=0$ ( $m$ is corrector iteration counter)

(c) $\quad m=m+1$

Solve the transport equation of $\varepsilon$ (equation (10)).

Repeat from (c) until convergence of $\varepsilon$ is achieved

$L^{(i)}=(1-\alpha) L^{(i-1)}+\alpha\left(k^{(i)}\right)^{3 / 2} / \varepsilon^{(i)} ; \quad 0<\alpha \leqslant 1$

Update $\mu^{\mathrm{t}}$ from equation (4).

Repeat from (a) until convergence is achieved in an L-norm. 
The underrelaxation used to update $L$ causes a smoother behaviour of the turbulent viscosity, calculated as $\mu^{\mathrm{t}}=C_{\mu} \rho \sqrt{k} L$, than the behaviour of the turbulent viscosity, calculated as $\mu^{\mathrm{t}}=\left(C_{\mu} \rho k^{2}\right) / \varepsilon$, obtained when using a classical $k-\varepsilon$ model.

When we fix the counter $j$ and $m$ in zero and $\alpha=1$, our algorithm is transformed in a classical staggered solution of the $k-\varepsilon$ model.

\section{TRANSPORT OF A SUBSTANCE}

The analysis of a tracer dispersion is carried out by solving an additional time-dependent concentration equation:

$$
\frac{\partial c}{\partial t}+\mathbf{v} \cdot \nabla c=\nabla \cdot\left[\left(D+D^{\mathrm{t}}\right) \nabla c\right]
$$

where $c$ is the time-averaged concentration of the injected substance, $D$ the molecular diffusivity $D^{\mathrm{t}}$ the turbulent diffusivity; $D^{\mathrm{t}}=\mu^{\mathrm{t}} / \rho$.

Equation (11) is a typical convection-diffusion equation in transient state with a non-constant

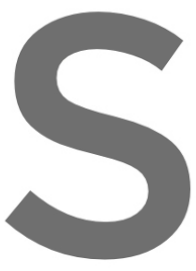
diffusion coefficient. It $[35-36]$ and a standar
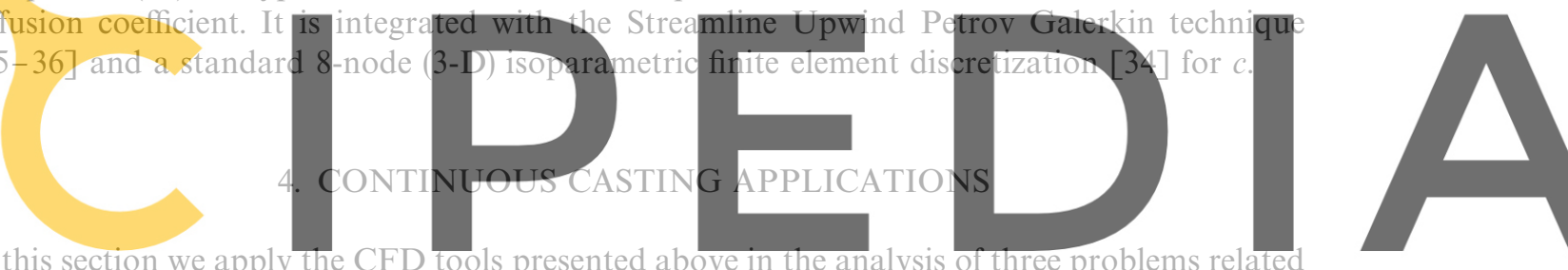

to industrial continuous casting installations for steel products.

\section{or free at https//wWw.scipedia.com to download}

4.1. Submerged entry nozzles

The output of the numerical models is used to judge the SEN designs taking into consideration the following requirements:

(i) The steel flow entering the mold should be carried to the meniscus in order to increase its temperature [38].

(ii) The flow at the mold exit should be as close as possible to a plug flow [38].

(iii) The flow should not disturb the surface in order not to remove the casting powders [38].

(iv) The flow should transport non-metallic inclusions to the casting powders [39].

(v) To avoid clogging the flow inside the SEN should not present recirculation zones [40].

4.1.1. Design of a SEN for a round mold. The liquid steel flow inside a round mold is analysed for five SEN designs:

(a) design A: direct out-flow (1 hole),

(b) design B: lateral out-flow, straight holes (4 holes),

(c) design $C$ : lateral out-flow, inclined holes (4 holes),

(d) design $D$ : combination of $\mathrm{A}+\mathrm{B}$ (5 holes).

In Figure 2 we show the scheme nozzle/mold. 
In Figure 3, the velocity map and turbulence intensity $(I t=\sqrt{k})$ map obtained for the C-design are shown (casting speed $=1.4 \mathrm{~m} / \mathrm{min}$ ). The boundary conditions are:

$\checkmark$ Inflow of liquid steel (e)

$v_{\mathrm{e}}^{\mathrm{n}}$ is the normal velocity depends on the continuous casting speed, $v_{\mathrm{e}}^{\mathrm{t}}=0$ is the tangential velocity, $k_{\mathrm{e}}=0 \cdot 01\left(v_{\mathrm{e}}^{\mathrm{n}}\right)^{2}$, References 7 and $20, \varepsilon_{\mathrm{e}}=k_{\mathrm{e}}^{3 / 2} /\left(d_{\mathrm{b}} / 2\right)$

$\checkmark$ Mold wall

The wall function, $\Delta=5 \mathrm{~mm}$

$\checkmark$ Free surface of the steel, meniscus, (s)

$v_{\mathrm{s}}^{\mathrm{n}}=0$, normal velocity to the surface

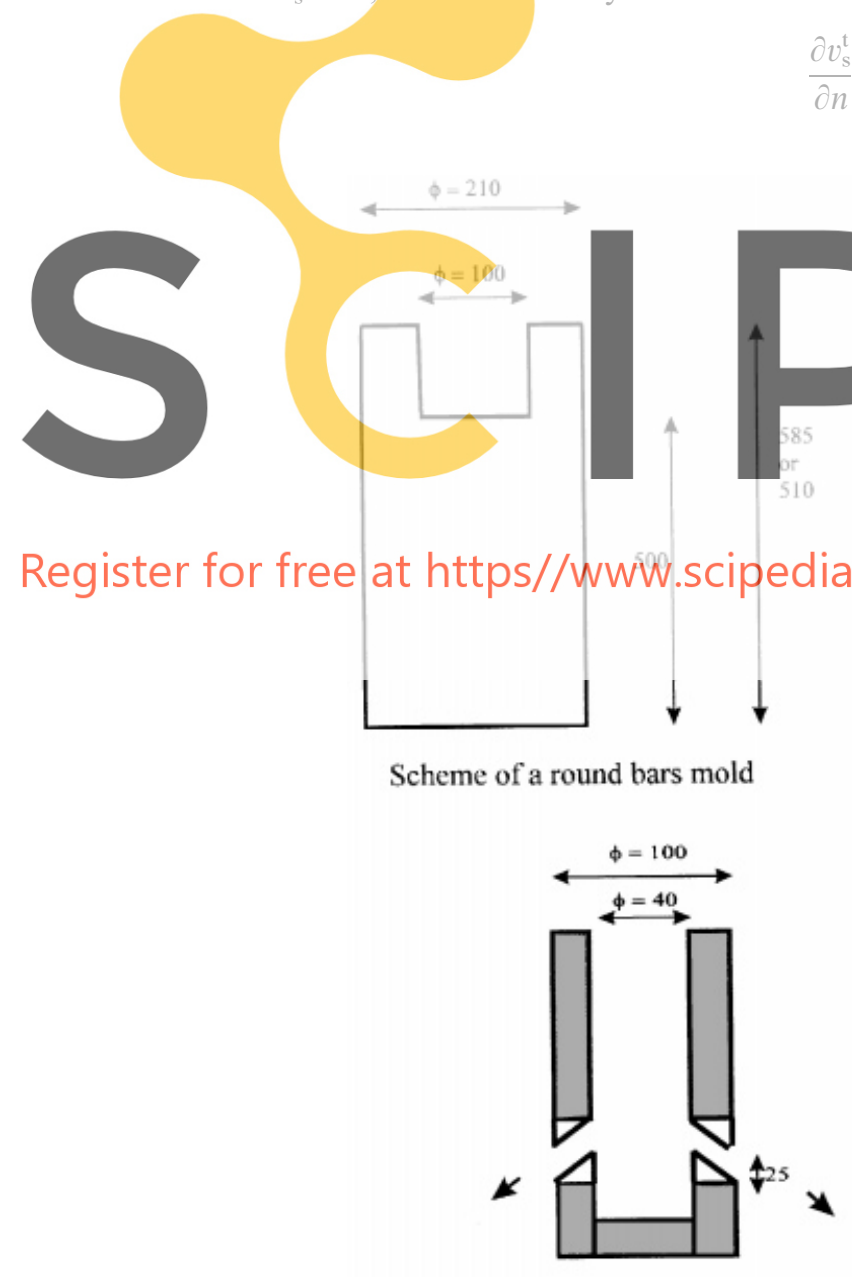

Design $\mathrm{C}$ $\frac{\partial v_{\mathrm{s}}^{\mathrm{t}}}{\partial n}=\frac{\partial k_{\mathrm{s}}}{\partial n}=\frac{\partial \varepsilon_{\mathrm{s}}}{\partial n}=0$
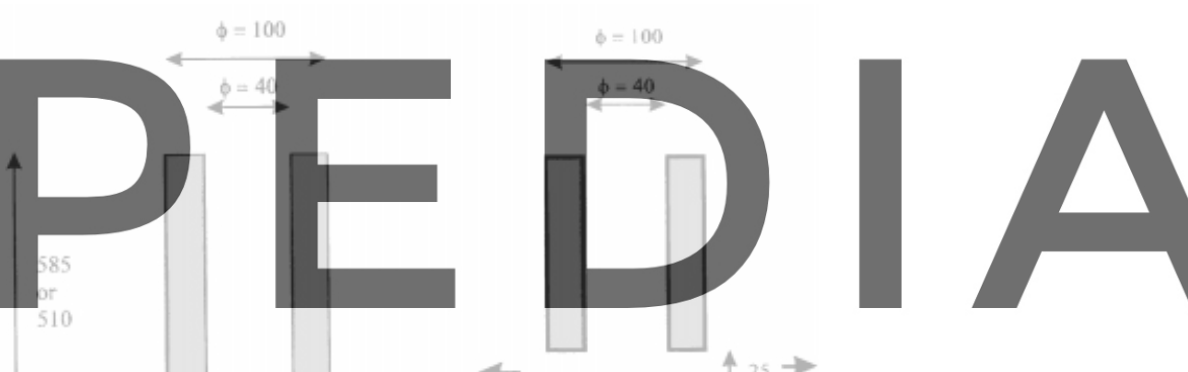


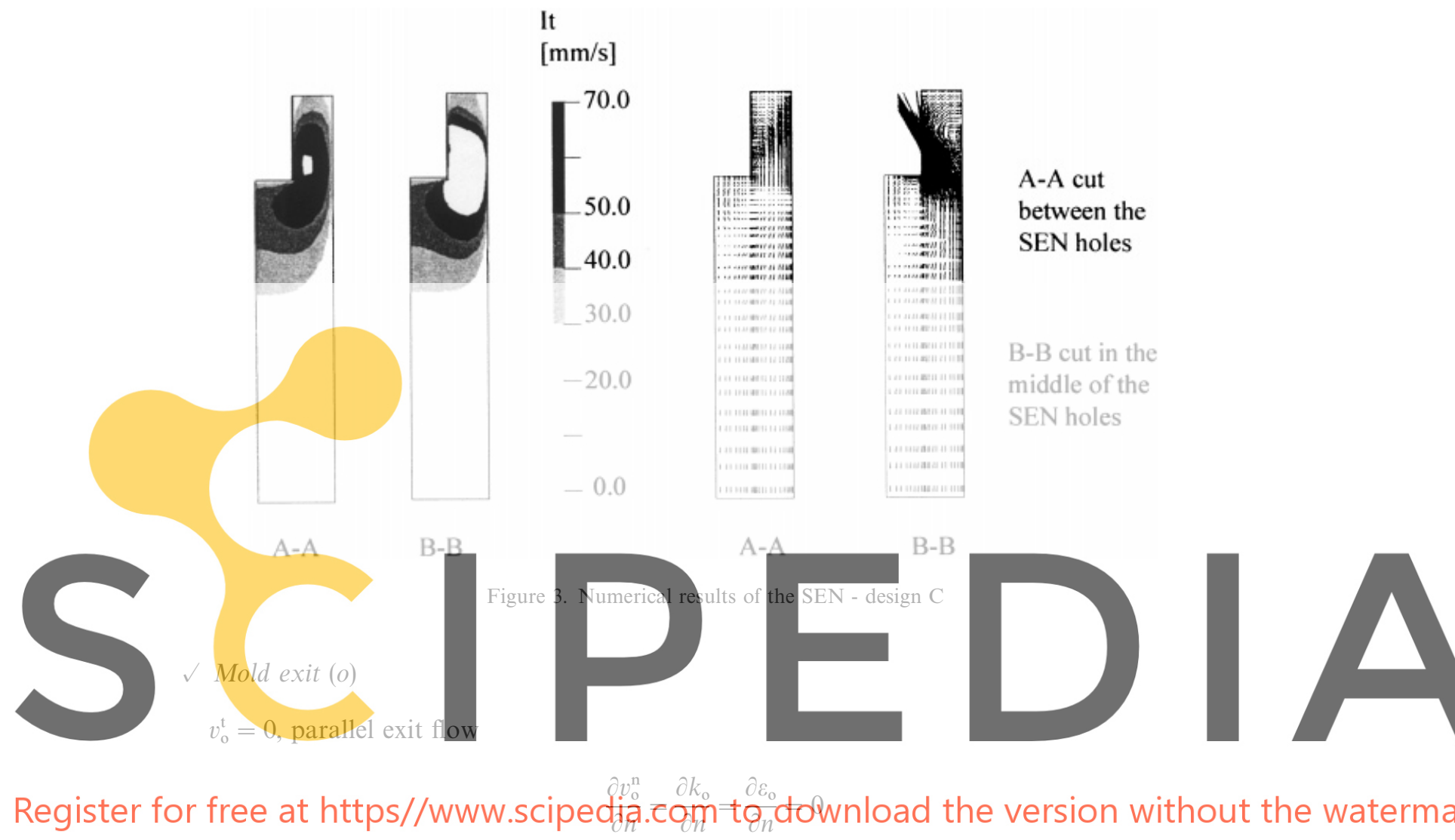

The numerical results provide information on:

(a) flow and mixing intensity at the meniscus,

(b) flow and mixing intensity at the locations inside the mold stagnation zones,

(c) flow friction on the mold wall.

The effect of different operational variables is also analysed for some of the SEN designs, among them:

(1) Liquid steel level in the mold

In case of using direct out-flow nozzles (design A) the higher the liquid steel in the mold the bigger the dead zone in the meniscus.

In case of using lateral out-flow nozzles (designs B, C, D) the recirculation flow in the meniscus zone is bigger.

(2) Casting speed

The continuous casting speed can change approximately 50 per cent. Then, the flow presents a similar behaviour except for the velocity module.

(3) Turbulence intensity in the inflow

The dimension of the inflow jet in the mold increases as the turbulence intensity increases. 
SIDERCA continuous casting process engineers built a $1: 1$ water model of the round mold, including the SEN.

In Figure 4 we show the numerical results and experimental results when using an injection of die tracer $\left(\mathrm{KMnO}_{4}\right)$ into the inlet water stream for the design A.

In Figure 5 we show the velocity and turbulence intensity distribution inside the SEN in the round bars continuous casting at TAMSA (Veracruz, Mexico).

The step inside the nozzle induces a recirculation zone that can lead to 'clogging' [40].

4.1.2. Slabs continuous casting. In general, the nozzles for slab mold have a lateral out-flow. Figure 6 shows the model domain (stopper rod/nozzle). As the stopper rod is centred in the cavity an approximately axisymmetric flow is obtained. The highest turbulence intensity is developed at the entrance of the ring space (stopper rod/nozzle). A fully developed flow was reached at $300 \mathrm{~mm}$ from the stopper rod. This fact will allow a detailed study of the stopper rod and the nozzle flow separately.

As recirculation occurs in the out-flow walls of the nozzle, it is not possible to have a complete description of the flow using ad-hoc 2-D models.

In Figure 7 it can be seen that the jet does not follow exactly the inclination of the outflow, so it is interesting to know the real values of the angles anc of the jet velocities. The following weighter

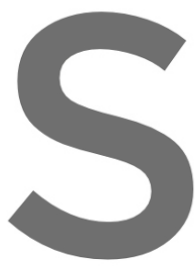
averages have been calcul
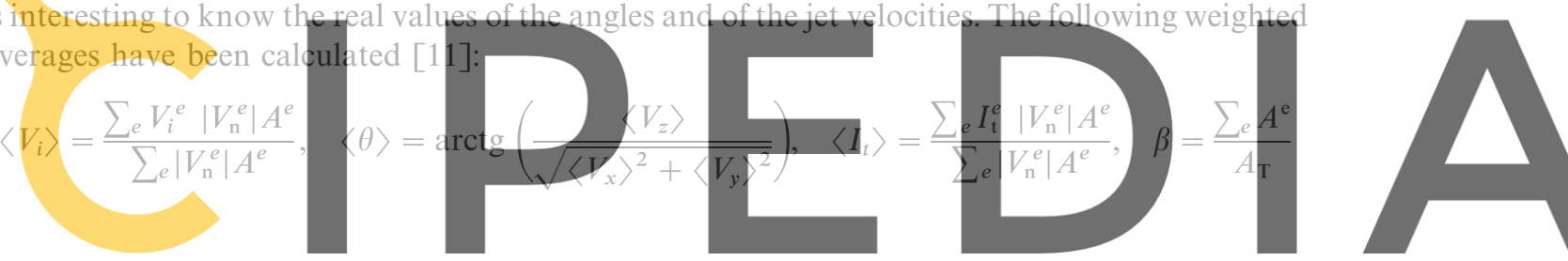

Register for free at https//www.scipedia.com to download the version without the waterma
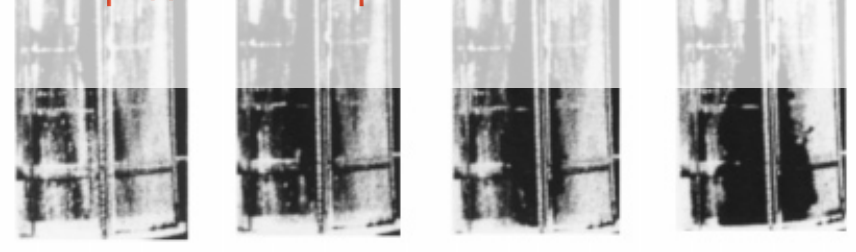

It
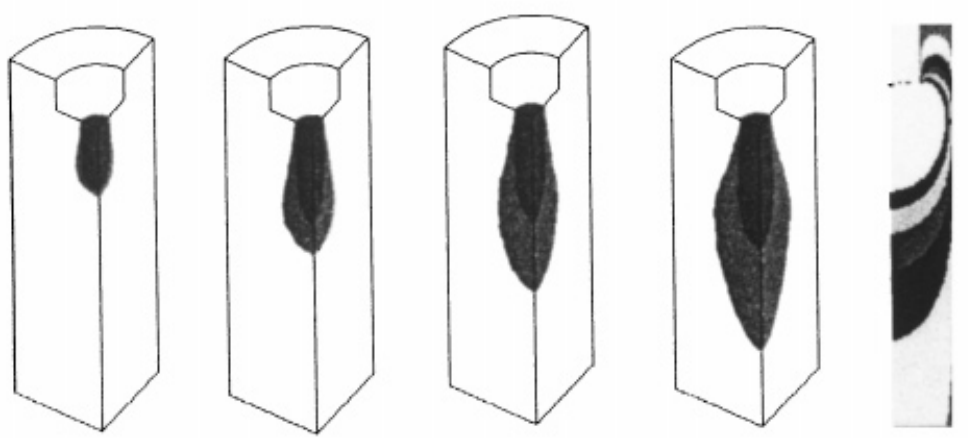

70.

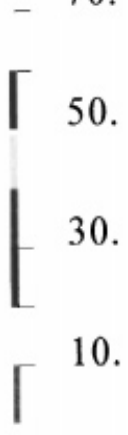

Figure 4. A-design SENs 


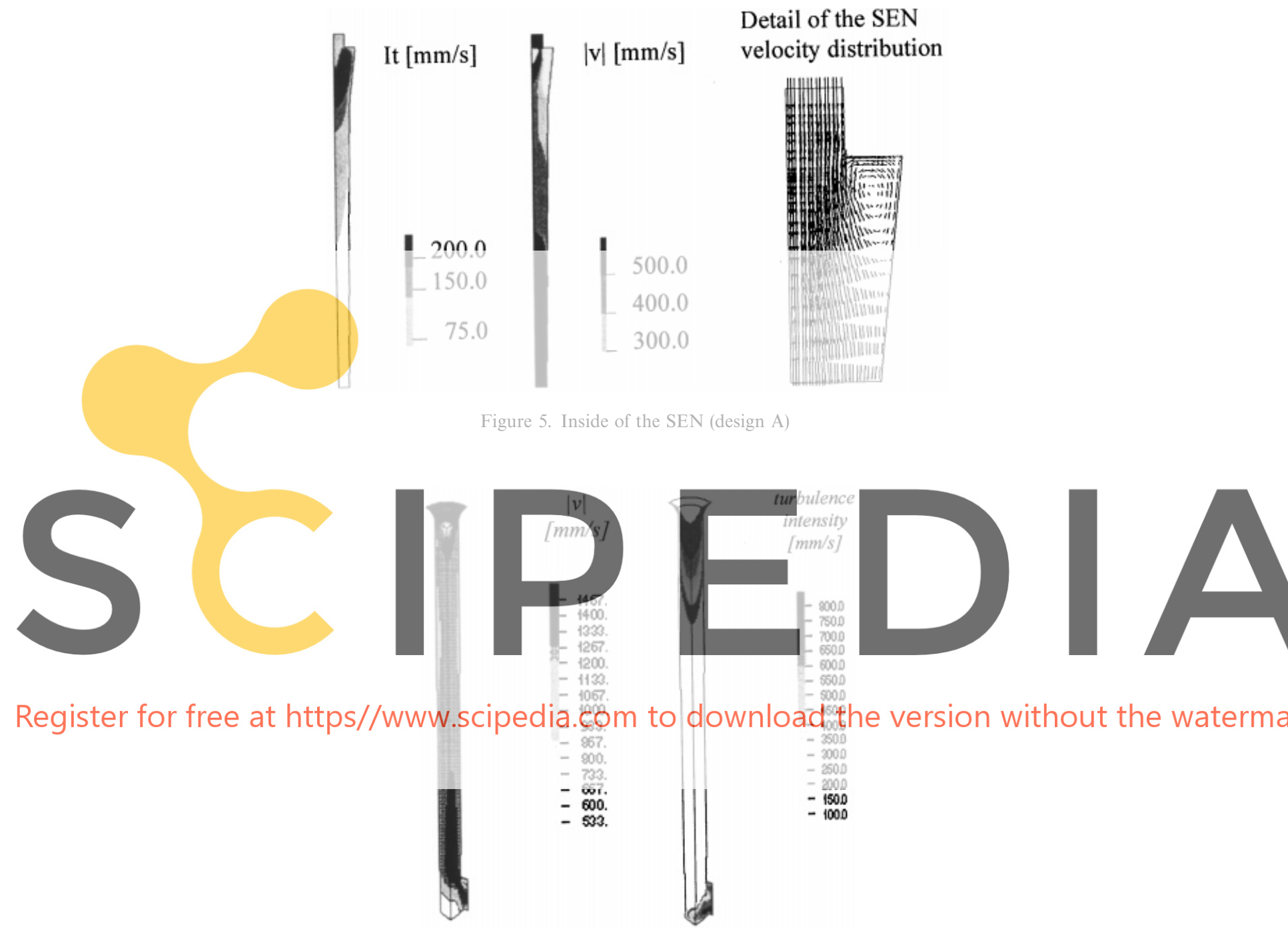

Figure 6. Stopper rod and SEN for slab mold

where $\left\langle V_{i}\right\rangle$ is the mean jet velocity in the $x, y$ and $z$ directions, $\left|V_{\mathrm{n}}^{e}\right|$ the absolute value of the mean normal velocity, $\langle\theta\rangle$ the mean jet angle, $\left\langle I_{t}\right\rangle$ the mean jet turbulence intensity, $\beta$ the fraction of the lateral outlet area, $V_{i}^{e}$ the mean jet speed in the element $e$ in the $x, y$ and $z$ directions, $I_{\mathrm{t}}^{e}$ the mean turbulence intensity in the element $e, A^{e}$ the area of the element $e$ in the lateral outlet, $A_{\mathrm{T}}$ the modelled total area of the lateral outlet, and $\sum_{e}$ shows an addition of the lateral outlet elements where there is liquid steel outflow (it does not include the recirculation elements of the lateral outlet).

In Figure 7 we show the details of the SEN for a medium rate flow, $Q_{\text {mid }}=4 \cdot 01 \times 10^{6} \mathrm{~mm}^{3} / \mathrm{s}$. Approximately 66 per cent of the liquid steel goes out through the 33 per cent of the available 

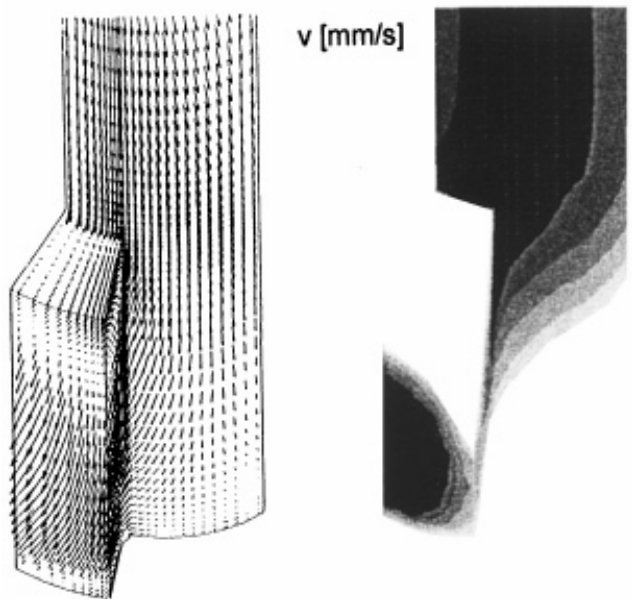

$|\mathrm{v}|[\mathrm{mm} / \mathrm{s}]$

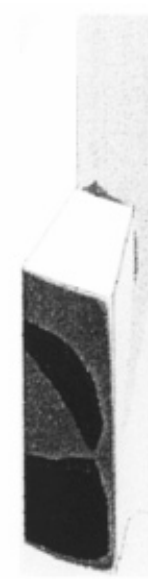

$\mathrm{I}_{\mathrm{t}}[\mathrm{mm} / \mathrm{s}]$

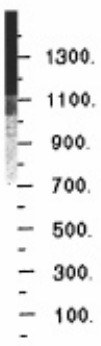

Figure 7. Detail of the lateral SEN

Table II. Calculated values at the port outlet

\begin{tabular}{lcccccccccc}
\hline $\begin{array}{l}\text { Rate flow } \\
\left(\mathrm{mm}^{3} / \mathrm{s}\right)\end{array}$ & $\begin{array}{c}V_{\mathrm{c}} \\
(\mathrm{m} / \mathrm{min})\end{array}$ & $\begin{array}{c}w \\
(\mathrm{~mm})\end{array}$ & $\begin{array}{c}\left\langle V_{x}\right\rangle \\
(\mathrm{mm} / \mathrm{s})\end{array}$ & $\begin{array}{c}\left\langle V_{y}\right\rangle \\
(\mathrm{mm} / \mathrm{s})\end{array}$ & $\begin{array}{c}\left\langle V_{z}\right\rangle \\
(\mathrm{mm} / \mathrm{s})\end{array}$ & $\begin{array}{c}\langle V\rangle \\
(\mathrm{mm} / \mathrm{s})\end{array}$ & $\langle\theta\rangle$ & $\begin{array}{c}\left\langle I_{\mathrm{t}}\right\rangle \\
(\mathrm{mm} / \mathrm{s})\end{array}$ & $\beta$ & $\left\langle I_{\mathrm{t}}\right\rangle /\langle V\rangle$ \\
\hline $2.52 \times 10^{6}$ & 1.05 & 780 & 592 & 99 & -397 & 719 & $33 \cdot 5$ & 217 & $0 \cdot 73$ & $0 \cdot 30$ \\
$4.01 \times 10^{6}$ & 1.05 & 1240 & 925 & 159 & -623 & 1127 & $33 \cdot 6$ & 368 & 0.75 & $0 \cdot 33$ \\
$7 \cdot 29 \times 10^{6}$ & 1.45 & 1630 & 1687 & 294 & -1119 & 2046 & $33 \cdot 2$ & 658 & 0.75 & $0 \cdot 32$ \\
\hline
\end{tabular}

outlet area; the other 34 per cent of the liquid steel goes out through the 42 per cent of the outlet area of the nozzle and in the remaining 25 per cent of the area there is a recirculating flow.

Table II shows the numerical results at the port outlet for different operating conditions. The results of the mean values show that the:

(1) mean jet angle is not a function of the rate flow,

(2) mean jet turbulence intensity increase when the rate flow increases,

(3) fraction of the lateral outlet area does not change with the rate flow,

(4) relation between the turbulence intensity and velocity at the outlet port does not change with the rate flow.

In Figure 8 we present a lateral SEN design used at SIDERAR (San Nicolas, Argentina) in its slabs continuous casting installation for two mold widths [13].

From Figure 8 one can see that:

$\checkmark$ the narrower mold has a shortest flow development,

$\checkmark$ there is a higher turbulence intensity inside the mold when the width is smaller,

$\checkmark$ the areas of low liquid steel movement are observed in the mold centre in maximum width molds. 

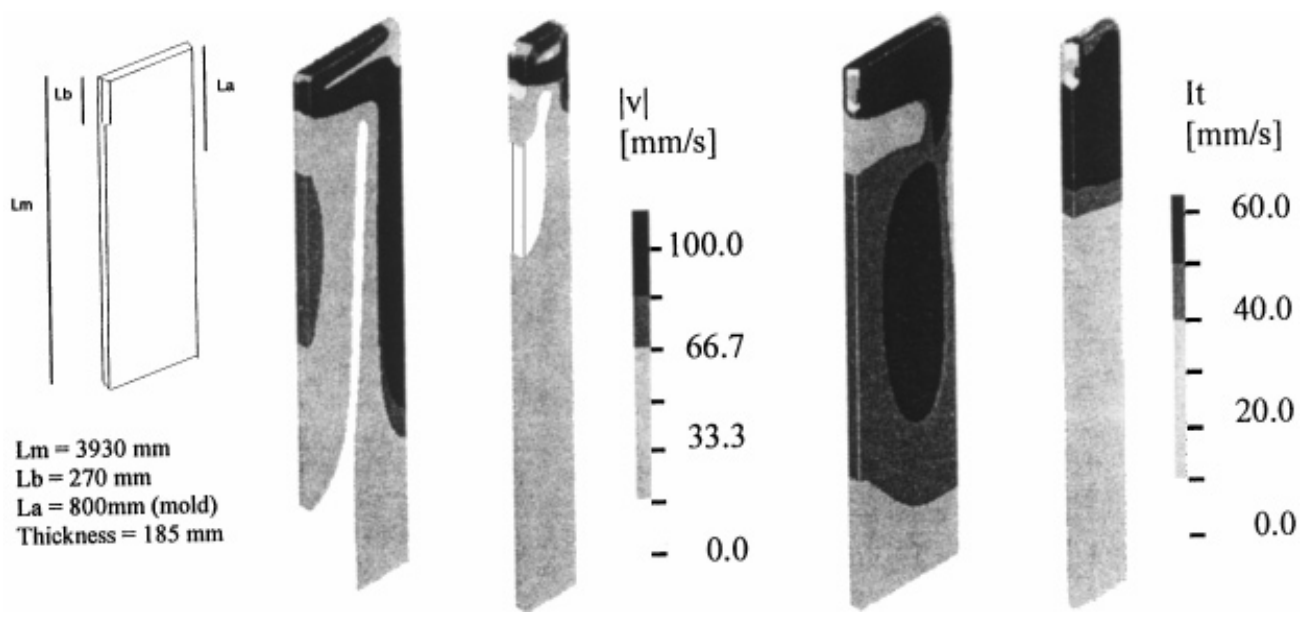

Figure 8. Slabs continuous casting

\subsection{Tundish}

The tundish $[5,8,9]$ is a refractory vessel placed between the ladle and the mold to supply and distribute the liquid steel to different SENs.

In the tundish the non-metallic inclusions have to float to the free surface and be trapped by the slag layer. The jet of liquid metal from the ladle to the tundish generates a high turbulence zone that induces possible oxidation of the liquid steel.

Therefore, the velocity distribution inside the tundish has a strong influence on the removal of inclusion particles and the re-oxidation of liquid steel.

In the present paper we study two different designs of flow control devices:

(1) the baffle with holes,

(2) the impact pad.

In Figure 9 we show the numerical results of turbulence intensity for the two devices. In both cases 2-D symmetric approximations were made.

From results in Figure 9 it can be seen that when using the impact pad the liquid steel free surface has less turbulence; this is a favourable feature for the slag inclusions removing function.

\section{CONCLUSION}

The iterative algorithm $(k-L)$-predictor/( $(\varepsilon)$-corrector scheme for solving turbulent flows $[1,4]$ was applied to the analysis of different continuous casting processes.

In this paper three application examples were shown:

1. The analysis of different SEN options in the mold of round bars continuous casting mold.

2. The analysis of one SEN design operating with different mold sizes in slabs continuous casting. 

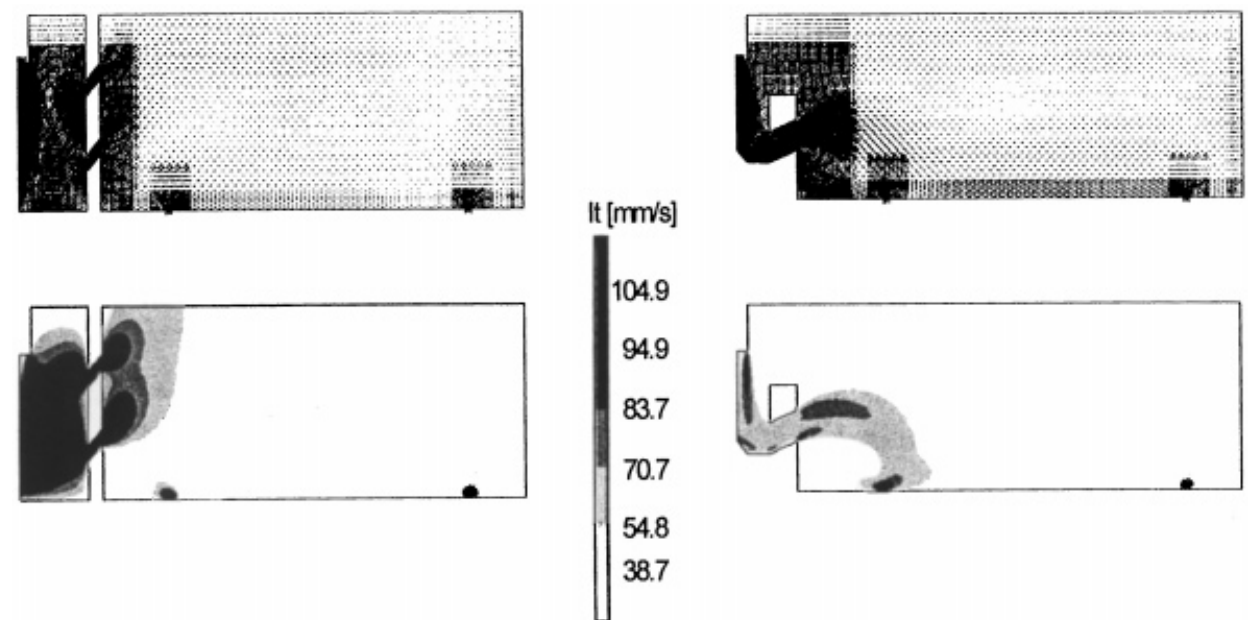

Figure 9. Velocity and turbulence intensity distribution in the tundish

3. The tundish of a continuous casting installation.

These examples showed that the algorithm developed can be used to obtain solutions of $k-\varepsilon$ turbulent model equations even in 3-D complex geometry situations.

The numerical model is used as an engineering tool for understanding and optimizing the steelmaking processes.

\section{ACKNOWLEDGEMENTS}

We gratefully acknowledge Dr. Eduardo N. Dvorkin for his help and the support for this research from SIDERCA (Argentina), TAMSA (Mexico) and SIDERAR (Argentina).

\section{REFERENCES}

1. Goldschmit MB, Cavaliere MA. An iterative $(k-L)$-predictor/( $(\varepsilon)$-corrector algorithm for solving $(k-\varepsilon)$ turbulent models. Engineering Computations 1997; 14(4):441-455.

2. Goldschmit MB, Cavaliere MA. Modeling of turbulent recirculating flows via an iterative $(k-L)$-predictor/ (E)-corrector scheme. Applied Mechanics Reviews 1995; 48:11.

3. Goldschmit MB, Cavaliere MA. Numerical solution of turbulent recirculating flows with an iterative $(k-L)$ predictor/( $(\varepsilon)$-corrector scheme. The Fourth Pan American Congress of Applied Mechanics, Buenos Aires, Vol. III. 1995; 89-94.

4. Goldschmit MB, Cavaliere MA, Radovitzky RA. A predictor-corrector iterative scheme for solving $k-\varepsilon$ model equations. The Third World Congress on Computational Mechanics, IACM-WCCM III, Japan, Vol. 1. 1994; 184-185.

5. Szekely J, Evans JW, Brimacombe JK. The Mathematical and Physical Modeling of Primary Metals Processing Operations. Wiley: New York, 1988.

6. Szekely J. Some perspectives on mathematical modelling of metal processing operations. Ironmaking and Steelmaking 1989; 16:3.

7. Thomas BG. Application of mathematical models to the continuous slab casting mold. Iron \& Steelmaker 1991; 53-66.

8. Chakraborty S, Sahai Y. Mathematical modelling of transport phenomena in continuous casting tundishes. Part 1: Transient effects during ladle transfer operations. Part 2: Transient effects owing to varying ladle stream temperature. Ironmaking and Steelmaking 1992; 19(6):488-494. 
9. Choudary SK, Mazundar D. Mathematical modelling of transport phenomena in continuous casting of steel. ISIJ International 1994; 34(7):584-492.

10. Najjar FM, Thomas BG, Hershery DE. Numerical study turbulent flow through bifurcated nozzles in continuous casting. Metallurgical Transactions B 1995; 26:749-765.

11. Choudary SK, Mazundar D. Mathematical modelling of fluid flow, heat transfer and solidification phenomena in continuous casting of steel. Steel Research 1995; 66(5):199-205.

12. Goldschmit MB. Computational fluid mechanics applications in continuous casting. 80th Steelmaking Conference Proceedings, Chicago, US. 1997; 337-341.

13. Dvorkin EN, Goldschmit MB, Cavaliere MA. Computational mechanics applications at SIDERAR steel mill. Second International Congress on Metallurgy and Materials Technology, ABM, São Paulo, Brazil, October, 1997.

14. Launder BE, Spalding DB. The numerical computation of turbulent flows. Computer Methods in Applied Mechanics and Engineering 1974; 3:269-289.

15. Markatos NCG, Spalding DB, Tatchell DG, Vlachos N. A solution method for three-dimensional turbulent boundary layers on bodies of arbitrary shapes. Computer Methods in Applied Mechanics and Engineering 1978; 15:161-174.

16. Rodi W. Turbulence Models and Their Application in Hydraulics. A state of the art review. International Association for Hydrualic Research: The Netherlands, 1980.

17. Smith M, On the finite element calculation of turbulent flow using the $k-\varepsilon$ model. International Journal for Numerical Methods in Fluids 1984; 4:303-319.

18. Smith M. A practical method of two-equation turbulence modelling using finite elements. International Journal for Numerical Methods in Fluids 1984; 4:321-336.

19. FANTOM, User manual, International Center for Numerical Methods in Engineering, 1994.

20. Joo S, Guthrie RIL. Inclusion behavior and heat-transfer phenomena in steelmaking tundish operations. Part I: Aqueous modeling. Metallurgical Transactions B 1993; 24B:755-765.

21. Honeyands T, Herbertson J. Fluid dynamics in thin slab caster moulds. Steel Research 1995; 66(7): 287-293.

22. Mazumdar D, Yamanoglu G, Guthrie RIL. Hydrodynamic performance of steelmaking tundish systems: a comparative study of three different tundish designs. Steel Research 1997; 68(7):293-300.

23. Joo S, Han JW, Guthrie RIL. Inclusion behavior and heat-transfer phenomena in steelmaking tundish operations. Part II: Mathematical model for liquid steel in tundishes. Metallurgical Transactions B 1993; 24B:767-777.

24. Reza Aboutalebi M, Hasan M, Guthrie RIL. Coupled turbulent flow, heat and solute transport in continuous casting processes. Metallurgical Transactions B 1995; 26B:731-744.

25. Morgan K, Hughes TG, Taylor C. The analysis of turbulent, free shear, and channel flows by the finite element method. Computer Methods in Applied Mechanics and Engineering 1979; 19:117-125.

26. Taylor C, Thomas CE, Morgan K. Modelling flow over a backward-facing step using the FEM and the two-equation model of turbulence. International Journal of Numerical Methods in Fluids 1981; 1:295-304.

27. Hackman LP, Raithby GD, Strong AB. Numerical predictions of flows over backward-facing step. International Journal of Numerical Methods in Fluids 1984; 4:711-724.

28. Betts PL, Haroutunian V. $k-\varepsilon$ modelling of turbulent flow over a backward facing step by a finite element method: comparison with finite volume solutions and experiments. Proceedings of the fourth International Conference on Numerical Methods in Laminar and Turbulent Flow, Swansea, UK, 1985; 574-585.

29. Benim AC, Zinser W. Investigation into the finite element analysis of confined turbulent flows using a $k-\varepsilon$ model of turbulence. Computer Methods in Applied Mechanics and Engineering 1985; 51:507-523.

30. Autret A, Grandotto M, Dekeyser I. Finite element computation of a turbulent flow over a two-dimensional backward facing step. International Journal of Numerical Methods in Fluids 1987; 7:89-102.

31. Utnes T. Two equation $(k-\varepsilon)$ turbulence computations by the use of a finite element model. International Journal of Numerical Methods in Fluids 1988; 8:965-975.

32. Ravisankar MS, Srinivas M, Seetharamu KN, Aswathanarayana PA, Reddy JN. Numerical analysis of turbulent flow and heat transfer over a backward facing step: comparison with experimental results. 29th National Heat Transfer Conference, Heat Transfer in Turbulent Flows, Vol. 246. ASME Heat Transfer Division Publication, 1993; 91-103.

33. Haroutinian V, Engelman MS. On modelling wall-bound turbulent flows using specialized near-wall finite elements and the standard $k-\varepsilon$ turbulence model. Advance in Numerical Simulations of Turbulent Flows, ASME FED, Vol. 117, 1991.

34. Zienkiewicz OC, Taylor RL. The Finite Element Method. Volume 1: Basic Formulation and Linear Problems. Volume 2: Solid and Fluid Mechanics Dynamics and Nonlinearity (4th edn), McGraw-Hill: London, 1989.

35. Hughes TJR, Brooks A. A theoretical framework for Petrov-Galerkin methods with discontinuous weighting functions: application to the streamline-upwind procedure. Finite Elements in Fluids 1982; 47-65.

36. Brooks A, Hughes TJR. Streamline upwind Petrov-Galerkin formulations for convection dominated flows with particular emphasis on the incompressible Navier-Stokes equations. Computer Methods in Applied Mechanics and Engineering 1982; 32:199-259. 
37. Codina R. A finite element model for incompressible flow problems. Doctoral Thesis Universidad Politecnica de Cataluña, 1992.

38. Ferretti A, Podrini M, Di Schino G. Submerged nozzle optimization to improve stainless steel surface quality at Terni Steelworks. In The Shrouding of Steel Flow for Casting and Teeming. Iron \& Steel Society, 1986; 45-54.

39. Mc Pherson NA. Continuously cast clean steel. In The Shrouding of Steel Flow for Casting and Teeming. Iron \& Steel Society, 1986; 31-43.

40. Rastogi R, Cramb AW. Clogging in liquid steel. CISR Progress Report, Sponsor CISR, 1996. 